\title{
Differences between infrared spectra of normal and neoplastic human gastric cells
}

\author{
Naoko Fujioka $^{\text {a }}$, Yuji Morimoto ${ }^{\mathrm{a}, *}$, Tsunenori Arai $^{\mathrm{b}}$, Kyoko Takeuchi $^{\mathrm{c}}$, Masahiko Yoshioka ${ }^{\mathrm{c}}$ \\ and Makoto Kikuchi ${ }^{\text {a }}$ \\ ${ }^{a}$ Department of Medical Engineering, National Defense Medical College, 3-2 Namiki, Tokorozawa, \\ Saitama 359-8513, Japan \\ ${ }^{\mathrm{b}}$ Department of Applied Physics and Physico-Informatics, the Faculty of Science and Technology, \\ Keio University, 3-14-1 Hiyoshi, Kohoku-ku, Yokohama, Kanagawa 223-8522, Japan \\ ${ }^{\mathrm{c}}$ First Department of Anatomy, National Defense Medical College, 3-2 Namiki, Tokorozawa, \\ Saitama 359-8513, Japan
}

\begin{abstract}
We investigated the differences in Fourier transform-infrared (FT-IR) spectra between normal and neoplastic human gastric cells. The infrared spectra derived from the cancer cells (AGS, SNU-1, and NCI-N87) showed a significant increase in infrared absorption in the band around $1240 \mathrm{~cm}^{-1}, 1120 \mathrm{~cm}^{-1}$ and $1080 \mathrm{~cm}^{-1}$, compared with those from the normal gastric epithelial cells we established in culture. In addition, frequency shifts of $4.6 \mathrm{~cm}^{-1}$ and $3.8 \mathrm{~cm}^{-1}$ were seen at the peak absorbance in the bands around $1240 \mathrm{~cm}^{-1}$ and $1080 \mathrm{~cm}^{-1}$, respectively. These spectral differences reflected the differences between the phosphate backbone in the normal and neoplastic human gastric cells. The present results suggest that FT-IR spectroscopy is a potential new tool for gastric cancer diagnosis.
\end{abstract}

\section{Introduction}

Gastric cancer is a leading cause of cancer death worldwide. Although its incidence has steadily decreased over the last six decades in the United States and Western Europe, gastric cancer remains the most common malignancy for both sexes in Asia and Latin America [1]. To reduce the incidence of this cancer, many efforts have been made to improve early diagnostic and therapeutic procedures.

Fourier transform infrared (FT-IR) spectroscopy is a sensitive analytical technique with practical advantages. It requires only small samples and allows non-destructive analysis of structural and chemi$\mathrm{cal} /$ physical properties of samples at the molecular level [2,3]. Recently, FT-IR spectroscopy has been extensively used as a cancer diagnostic technique because of its potential for revealing biological changes in diseased cells in the process of carcinogenesis [4-7]. Cohenford et al. showed that the FT-IR spectra of pelleted exfoliated cells from patients with cervical cancer or dysplasia differed from those of such cells from normal women [4]. In addition, differences between FT-IR spectra of colon adenocarcinoma cells and normal colon tissues have been reported [8]. However, there have been no reports comparing FT-IR spectra of normal and neoplastic human gastric cells. Therefore, in the present study, we investigated the differences between FT-IR spectra of normal gastric cells and gastric cancer cells to clarify the IR spectral features of gastric cancer cells. For this purpose, we have established normal gastric epithelial cell lines and used these cells as the control for comparison with gastric cancer cells. Herein we show

\footnotetext{
*Corresponding author: Yuji Morimoto, MD, PhD, Department of Medical Engineering, National Defense Medical College, 3-2 Namiki, Tokorozawa, Saitama 359-8513, Japan. Fax: +81 42996 5199; E-mail: moyan@cc.ndmc.ac.jp.
} 
the essential difference in FT-IR spectra between normal and neoplastic human gastric cells, indicating the great potential of FT-IR as a practical diagnostic tool for gastric cancer.

\section{Materials and methods}

\subsection{Gastric mucosal epithelial cells}

Human gastric mucosal epithelial cells were prepared using a modified method of Wagner et al. [9], and initiation of the primary culture was based on the methods of Bagchi et al. [10] and Basque et al. [11]. Normal stomach tissues were obtained from 8 randomly selected patients (mean age, $62 \mathrm{y} / \mathrm{o}$, ranging from 48 to $80 \mathrm{y} / \mathrm{o}$ ) undergoing gastrectomy at the National Defense Medical College. The appropriate ethics committees approved the study, and all patients gave their informed consent. Surgical specimens $\left(4-6 \mathrm{~cm}^{2}\right)$ were taken from a pathologically healthy part of the body and antrum region of the removed stomach. The tissue specimens were chopped into small cubes $\left(3 \times 3 \times 3 \mathrm{~mm}^{3}\right)$ and both the mucosal epithelium and the lamina propria mucosae were sliced off from the cubic samples. The sliced specimens were centrifuged at 50-100 $\mathrm{g}$ for $5 \mathrm{~min}$ and the resulting pellets were stirred in phosphate buffered saline (PBS) containing $0.2 \%(w / v)$ collagenase type I (Wako, Osaka, Japan) and 1\% (w/v) DNase I (Roche Diagnostics GmbH, Mannheim, Germany) for a few seconds. They were then incubated to dissociate the cells for $15 \mathrm{~min}$, and the dissociated cells were filtered through a nylon mesh (pore $=40 \mu \mathrm{m}$ ) and collected and centrifuged at 50-100g for $10 \mathrm{~min}$. After discarding the supernatant PBS, the cells were resuspended and re-centrifuged. The resulting pellets were seeded in a collagen-coated plastic culture dish with a 5-ml medium (Keratinocyte-SFM, Gibco, Invitrogen, Carlsbad, CA) containing penicillin (100 U/ml), streptomycin $(50 \mu \mathrm{g} / \mathrm{ml})$, and $10 \%$ fetal bovine serum (Gibco). The seeded cells were incubated at $37^{\circ} \mathrm{C}$ for $24 \mathrm{~h}$ in a humidified incubator in a $5 \% \mathrm{CO}_{2}$ atmosphere. When the cells reached confluence, the cells were passed by harvesting with $0.25 \%$ trypsin- 1 mM EDTA (Gibco) at $37^{\circ} \mathrm{C}$ and seeded. In order to maintain pure culture, we removed fibroblastic cells from the dishes using a silicon rubber scraper every $48 \mathrm{~h}$. For the FT-IR experiments, the primary culture cells were used.

To confirm whether the cultured cells had the characteristics of normal gastric mucosal epithelium, they were examined histochemically and morphologically. Expression of protein markers, including pepsin (Anti-Pepsin, Polysciences, Washington, PA), gastric mucin (MUC5AC, Labvision, Fremont, CA) and gastric $\mathrm{H}^{+} / \mathrm{K}^{+}$-ATPase (Anti- $\mathrm{H}^{+} / \mathrm{K}^{+}$-ATPase ( $\beta$-subunit), Affinity Bioreagents, Golden, $\mathrm{CO}$ ) was detected as described previously $[10,11]$. For ultrastructural analysis, the cultured cells were fixed with $2.5 \%$ glutaraldehyde-PBS for $1 \mathrm{~h}$ and then washed with PBS. They were postfixed in $1 \% \mathrm{OsO}_{4}-100 \mathrm{mM}$ phosphate buffer ( $\mathrm{pH}$ 7.4), dehydrated, and embedded in Epon. The horizontal ultrathin sections were examined by electron microscope.

\subsection{Gastric cancer cell lines}

Three human gastric adenocarcinoma cell lines, AGS (differentiation grade not known), SNU-1 (poorly differentiated), and NCI-N87 (well differentiated) were purchased from the American Type Culture Collection (ATCC, Manassas, VA). In the FT-IR experiment, cells were used at the 5th passage. The three cell lines were cultured by standard methodology and according to the specific instructions of the ATCC. 


\subsection{FT-IR measurement}

Confluent cells were harvested with $0.25 \%$ trypsin- 1 mM EDTA. The following preparation of cellular pellets was carried out at $4{ }^{\circ} \mathrm{C}$. The harvested cells were pelleted by centrifugation and a small amount (almost $0.01 \mathrm{mg}$ ) of the cell pellets was placed on a diamond window (Diamond Window ${ }^{\mathrm{TM}}, \phi=3 \mathrm{~mm}$, Sumitomo Electric, Tokyo, Japan). The pellets were air-dried for 3 min under atmospheric humidity $<60 \%$ [12]. The IR absorption spectrum of each pellet was obtained with a Fourier transform infrared spectrometer (FT/IR-620, Jasco, Tokyo, Japan) with a resolution of $2.5 \mathrm{~cm}^{-1}$. The size of the aperture $(100 \times 100 \mu \mathrm{m})$ allowed IR spectral measurement of $25 \sim 100$ gastric cells each time. In order to exclude a masking effect due to thickness of the sample, each IR spectrum was normalized by scaling the entire spectrum to the IR absorbance at $1650 \mathrm{~cm}^{-1}$ (amide I), thus showing that the IR absorbance at $1650 \mathrm{~cm}^{-1}$ was $100 \%$ absorbance.

\subsection{Statistical analysis for FT-IR spectra}

The frequency region of $1650-925 \mathrm{~cm}^{-1}$ was chosen for the analysis because previous studies have shown many differences between normal and cancerous cells in that region $[4,6]$. At each spectral wavenumber, a $t$-test for the difference between absorbances of normal cells and cancer cells was conducted, yielding one $P$ value per frequency.

\section{Results}

\subsection{Characteristics of gastric mucosal epithelial cells}

In the course of primary culture, we confirmed that the transferred cells first adhered to each other, and then began to spread, finally forming a monolayer of dense epithelial colonies. Individual cells displayed a polyhedral epithelial morphology. Tight junctions were present on the free surface (Fig. 1A). Numerous normal structural mitochondria were seen, in which the crista consisted of the inner mitochondrial membrane (Fig. 1B). Immunohistochemical examination revealed that every cell in the growing colonies

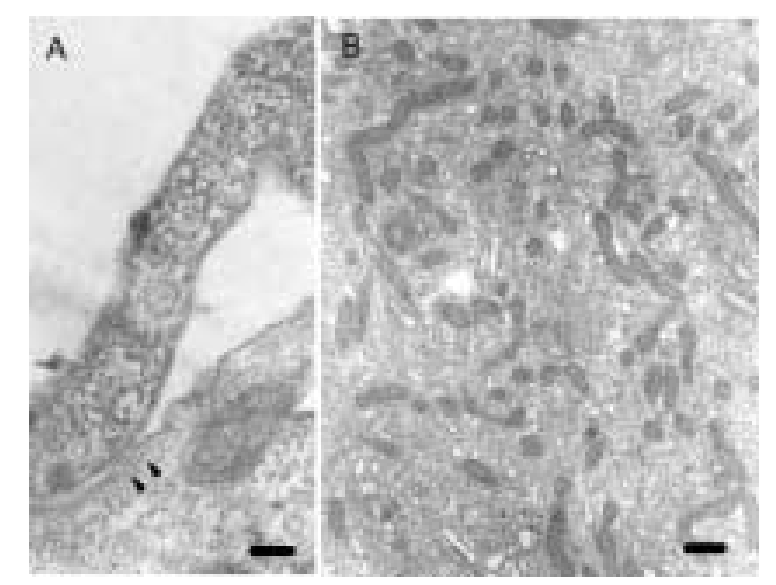

Fig. 1. Electron photomicrograph of gastric epithelial cells in primary cultures. Note the desmosome in the intracellular space $(A, \boldsymbol{\Delta}$ ) and the many normal mitochondria in the cytoplasm (B). Bar $=200 \mathrm{~nm}(\mathrm{~A})$, and $500 \mathrm{~nm}(\mathrm{~B})$. 
expressed either mucin, pepsin, or gastric proton pump $\left(\mathrm{H}^{+} / \mathrm{K}^{+}\right.$-ATPase $)$. These results indicated that these cultured cells originated from either surface mucinous cells/superficial epithelial cells, chief cells, or parietal cells. The integrity of the confluent monolayer remained unaltered for at least 2 months. Obvious differences among 8 cultured cells, each of which was obtained from a different patient, were not seen morphologically or histochemically.

\subsection{Features of IR absorption spectra of normal cells and cancer cells}

Figure 2A shows the mean IR absorbencies $\left(1650-925 \mathrm{~cm}^{-1}\right)$ of the normal gastric mucosal epithelial cells and three types of cancer cells. The gross spectral features of the IR spectra mostly resemble those

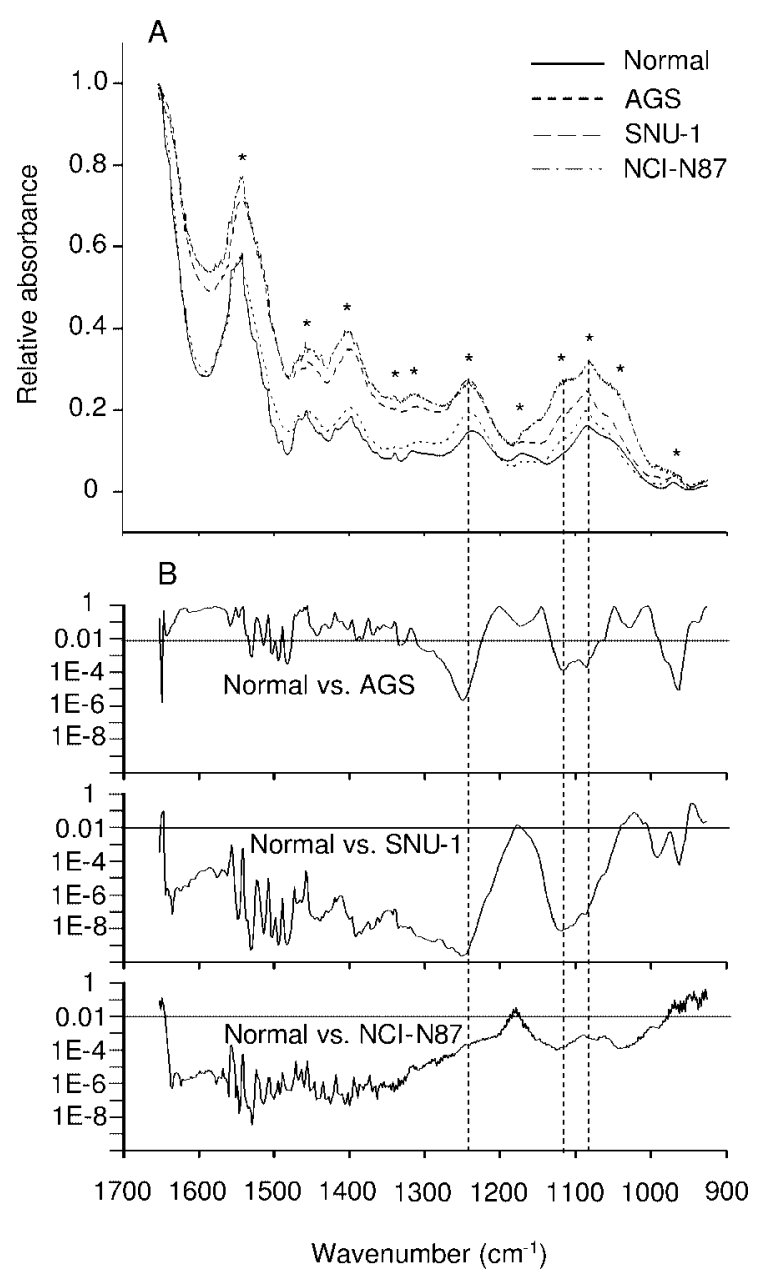

Fig. 2. A, IR absorbance spectra of normal mucosal epithelial cells and three types of gastric cancer cells. In the normal cells, spectrum represents a mean absorbance of 8 measurements, each of which was obtained from a different patient. In the cancer cells, spectrum represents a mean absorbance of 14, 7, and 5 measurements in AGS, SNU-1, and NCI-87, respectively. Each measurement of the cancer cells was obtained from a different cell sample. Each spectrum was normalized by scaling the entire spectrum to the IR absorbance at $1650 \mathrm{~cm}^{-1}$ (amide I). Asterisks indicate absorption bands. B, Statistical significance in IR absorbance of the normal cells versus each type of cancer cells, based on a $t$-test with unequal variances. Note the prominent differences in IR absorbance in the bands around 1240, 1120 and $1080 \mathrm{~cm}^{-1}$ (dotted lines parallel to $y$-axis). 
of other organ cells previously reported [4-7]. Figure 2B shows the $P$ values associated with tests for differences in absorbance between normal cells and cancer cells at each wavenumber. A $P$ value above 0.05 suggested that there was no significant difference in absorbance between normal and cancer cells, whereas a $P$ value below 0.05 indicated a significant difference. Eleven absorption bands (asterisks) were seen in the frequency range $\left(1650-925 \mathrm{~cm}^{-1}\right)$. Three bands out of the eleven bands showed notably small $P$ values $(<0.01)$ in any comparison tests (dotted lines parallel to $y$-axis). The three bands included a band having the maximum peak around 1240,1120 , and $1080 \mathrm{~cm}^{-1}$.

\subsection{IR absorptions at $1240 \mathrm{~cm}^{-1}, 1120 \mathrm{~cm}^{-1}$ and $1080 \mathrm{~cm}^{-1}$}

At the three wavenumbers $\left(1240,1120\right.$, and $\left.1080 \mathrm{~cm}^{-1}\right)$, IR absorbance values in any cancer cells were greater than those of normal cells (Fig. 3). In addition, significant differences were seen among the IR absorbance values of the three types of cancer cells. Apart from absorbance values, a significant frequency shift was seen in the bands around 1240 and $1080 \mathrm{~cm}^{-1}$ (Fig. 4). Around $1240 \mathrm{~cm}^{-1}$, peak maximum absorbance in normal cells was observed at $1236.9 \mathrm{~cm}^{-1}$ (mean) while cancer cells (AGS, SNU-1 and NCIN87) showed peak maximum absorbance at $1241.5 \mathrm{~cm}^{-1}$ (mean), indicating a $4.6-\mathrm{cm}^{-1}$ shift accompanying malignant alteration (Fig. 4). Similarly, peak maximum absorbance in the band around $1080 \mathrm{~cm}^{-1}$ shifted from $1081.9 \mathrm{~cm}^{-1}$ (normal) to $1085.7 \mathrm{~cm}^{-1}$ (AGS and SNU-1) as Fig. 4 shows. On the other hand, the peak appeared in NCI-N87 cells was observed at $1081.5 \mathrm{~cm}^{-1}$ (mean), indicating a $-0.4-\mathrm{cm}^{-1}$ shift when compared with that in normal cells (Fig. 4). However, the $-0.4-\mathrm{cm}^{-1}$ band shift was not significant since the spectral resolution in the present study was $2.5 \mathrm{~cm}^{-1}$, as described in the methods. Peak maximum absorbance in the band around $1120 \mathrm{~cm}^{-1}$ was not clear in the normal cells or AGS cells.

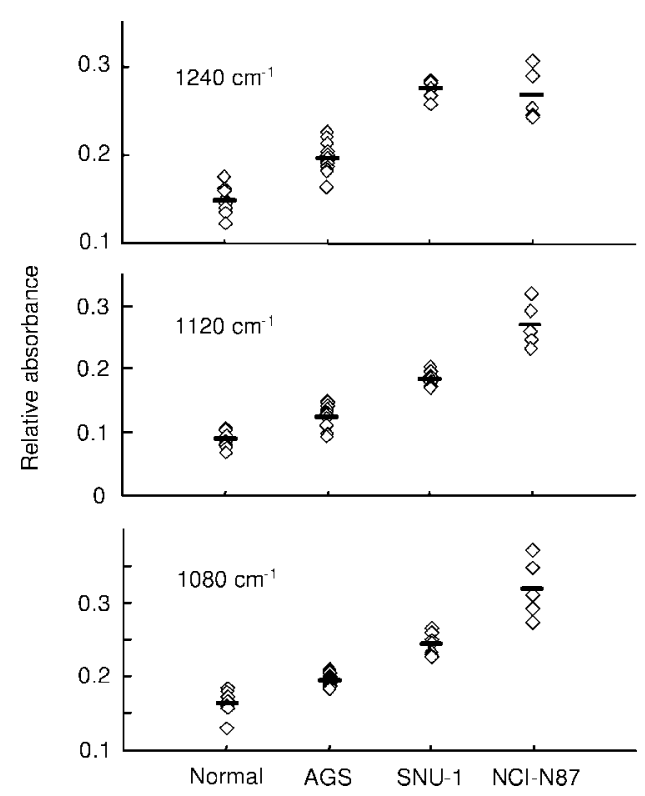

Fig. 3. IR absorbance of normal mucosal epithelial cells and gastric cancer cells, including AGS, SNU-1, and NCI-87 at the peak maximum in the band around $1240 \mathrm{~cm}^{-1}, 1120 \mathrm{~cm}^{-1}$ and $1080 \mathrm{~cm}^{-1}$. IR absorbances of any types of cancer cells are greater than those of normal cells in all three frequency bands. Each absorbance was normalized to the absorbance at $1650 \mathrm{~cm}^{-1}$. Bars indicate means. 

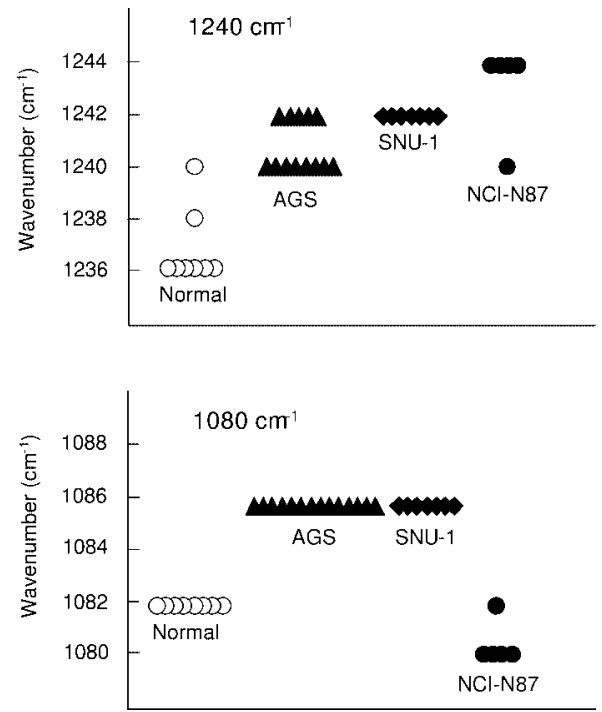

Fig. 4. Wavenumber at peak maximum absorbance in the band around $1240 \mathrm{~cm}^{-1}$ and $1080 \mathrm{~cm}^{-1}$. Around $1240 \mathrm{~cm}^{-1}$, wavenumber at peak maximum absorbance in normal cells $\left(1236.9 \mathrm{~cm}^{-1}\right)$ is significantly smaller than those in any cancer cells (AGS, $1240.7 \mathrm{~cm}^{-1}$; SNU-1, $1241.9 \mathrm{~cm}^{-1}$; NCI-N87, $1243.1 \mathrm{~cm}^{-1}$ ). In the band around $1080 \mathrm{~cm}^{-1}$, wavenumber at peak maximum absorbance in the two types of cancer cells (AGS and SNU-1) also shifts when compared with that in normal cells.

\section{Discussion}

\subsection{IR absorption in the bands around $1240 \mathrm{~cm}^{-1}, 1120 \mathrm{~cm}^{-1}$ and $1080 \mathrm{~cm}^{-1}$}

Three remarkable spectroscopic features were confirmed in human gastric cancer cells in the present study. First, IR absorption in the bands around $1240 \mathrm{~cm}^{-1}$ and $1080 \mathrm{~cm}^{-1}$ increased in these cells. Since these bands were previously identified to be the vibration mode of $\mathrm{PO}_{2}^{-}$of the phosphodiester groups [5], the increased IR absorption in these bands suggests an increase in nucleic acids [13]. Second, in the $1080-\mathrm{cm}^{-1}$ band, the absorption peak maximum appearing at $1081.9 \mathrm{~cm}^{-1}$ in the normal cells was shifted to $1085.7 \mathrm{~cm}^{-1}$ in two types out of three types of cancer cells. This shift can be attributable to the tighter packing of DNA molecules in the abnormal cells $[6,14,15]$. Apart from the $1080-\mathrm{cm}^{-1}$ band, the peak maximum in the band around $1240 \mathrm{~cm}^{-1}$ moved toward a higher frequency in the cancer cells, suggesting a change in hydrogen bonds in the phosphodiester groups of the DNA molecules in abnormal gastric cells [7,14]. Third, a significant increase in absorbance was seen in the shoulder band at $1120 \mathrm{~cm}^{-1}$ in the cancer cells. This band is due to increase in RNA contents in the cancer cells $[5,16]$. As explained, these three remarkable features are all related to an increase in the phosphate backbone. This increase in the phosphate backbone may correspond to increase in DNA and RNA content of the cancer cells.

\subsection{Application and limitation of FT-IR spectroscopy}

FT-IR makes it relatively easy to identify structural and chemical/physical properties at the molecular level. Thus, this method has been clinically employed to detect or classify cervical lesions. For the diagnosis of cervical cancer, the sensitivity has reached $79 \%$ when FT-IR is applied [10]. The limitations 
of the FT-IR method include the difficulty in measuring thick samples and water-rich samples. Nevertheless, FT-IR is a promising tool for cancer diagnosis because of the rapid processing time and the ease of operation, without the need for specialists. This method can be applied to exfoliative cells and small tissue obtained by biopsy. Our results strongly suggest that FT-IR spectroscopy is a useful technique for screening gastric cancer.

\section{Conclusion}

In the present study using FT-IR spectroscopy, we demonstrated the differences between infrared spectra of normal gastric epithelial cells and gastric cancer cells. Since the control IR absorption spectra were derived from the cultured normal gastric mucosal cells, the differences in IR absorbance between the normal gastric cells and cancer cells may, for the most part, reflect a purely biochemical difference in intra-cellular components as well as in the cellular membrane. These spectral differences were seen substantially in the bands around $1240 \mathrm{~cm}^{-1}, 1120 \mathrm{~cm}^{-1}$ and $1080 \mathrm{~cm}^{-1}$.

\section{Acknowledgements}

The authors gratefully acknowledge the Department of Surgery II, National Defense Medical College for supplying the gastric cancer tissue, and Drs. Yoshio Sawazaki and Masahiko Kuroki for performing part of the monoclonal assays. This work was supported by grants from the New Energy and Industrial Technology Development Organization (Tokyo, Japan).

\section{References}

[1] D.M. Parkin, P. Pisani and J. Ferlay, Estimates of the worldwide incidence of eighteen major cancers in 1985, Int. J. Cancer 54 (1993), 594-606.

[2] D.C. Malins and S.J. Gunselman, Fourier-transform infrared spectroscopy and gas chromatography-mass spectrometry reveal a remarkable degree of structural damage in the DNA of wild fish exposed to toxic chemicals, Proc. Natl. Acad. Sci. USA 91 (1994), 13038-13041.

[3] W.K. Surewicz, H.H. Mantsch and D. Chapman, Determination of protein secondary structure by Fourier transform infrared spectroscopy: a critical assessment, Biochemistry (Mosc.) 32 (1993), 389-394.

[4] M.A. Cohenford, T.A. Godwin, F. Cahn, P. Bhandare, T.A. Caputo and B. Rigas, Infrared spectroscopy of normal and abnormal cervical smears: evaluation by principal component analysis, Gynecol. Oncol. 66 (1997), 59-65.

[5] P.T.T. Wong, E.D. Papavassiliou and B. Rigas, Phosphodiester stretching bands in the infrared spectra of human tissues and cultured cells, Appl. Spectrosc. 45 (1991), 1563-1567.

[6] P.T.T. Wong, R.K. Wong, T.A. Caputo, T.A. Godwin and B. Rigas, Infrared spectroscopy of exfoliated human cervical cells: evidence of extensive structural changes during carcinogenesis, Proc. Natl. Acad. Sci. USA 88 (1991), 10988-10992.

[7] B. Rigas, S. Morgello, I.S. Goldman and P.T.T. Wong, Human colorectal cancers display abnormal Fourier-transform infrared spectra, Proc. Natl. Acad. Sci. USA 87 (1990), 8140-8144.

[8] B. Rigas and P.T. Wong, Human colon adenocarcinoma cell lines display infrared spectroscopic features of malignant colon tissues, Cancer Res. 52 (1992), 84-88.

[9] S. Wagner, W. Beil, U.E. Mai, C. Bokemeyer, H.J. Meyer and M.P. Manns, Interaction between Helicobacter pylori and human gastric epithelial cells in culture: effect of antiulcer drugs, Pharmacology 49 (1994), 226-237.

[10] D. Bagchi, T.R. McGinn, X. Ye, J. Balmoori, M. Bagchi, S.J. Stohs, C.A. Kuszynski, O.R. Carryl and S. Mitra, Mechanism of gastroprotection by bismuth subsalicylate against chemically induced oxidative stress in cultured human gastric mucosal cells, Dig. Dis. Sci. 44 (1999), 2419-2428.

[11] J.R. Basque, P. Chailler, N. Perreault, J.F. Beaulieu and D. Menard, A new primary culture system representative of the human gastric epithelium, Exp. Cell Res. 253 (1999), 493-502. 
[12] N. Fujioka, Y. Morimoto, K. Takeuchi, M. Yoshioka and M. Kikuchi, Difference in infrared spectra from cultured cells dependent on cell-harvesting method, Appl. Spectrosc. 57(2) (2003), 241-243.

[13] F.S. Parker, Applications of Infrared Raman and Resonance Raman Spectroscopy in Biochemistry, Plenum, New York, 1983.

[14] H.M. Yazdi, M.A. Bertrand and P.T.T. Wong, Detecting structural changes at the molecular level with Fourier transform infrared spectroscopy. A potential tool for prescreening preinvasive lesions of the cervix, Acta Cytol. 40 (1996), 664-668.

[15] E. Krupnik, M. Jackson, R.P. Bird, I.C.P. Smith and H.H. Mantsch, Investigation into the infrared spectroscopic characteristics of normal and malignant colonic epithelium, Proc. SPIE 3257 (1998), 307-310.

[16] H. Fabian, R. Wessel, M. Jackson, A. Schwartz, P. Lasch, I. Fichtner, H.H. Mantsch and D. Naumann, IR-spectroscopy and IR-microscopy of human breast tumors, xenografted breast tumors, and breast tumor cell lines, Proc. SPIE 3257 (1998), 13-23. 


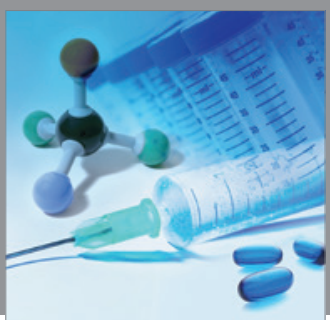

International Journal of

Medicinal Chemistry

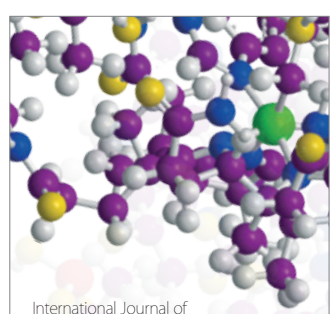

Carbohydrate Chemistry

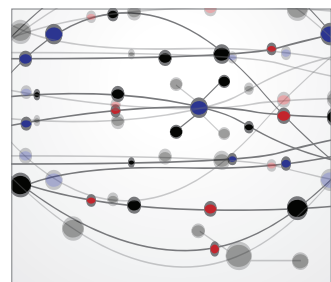

The Scientific World Journal
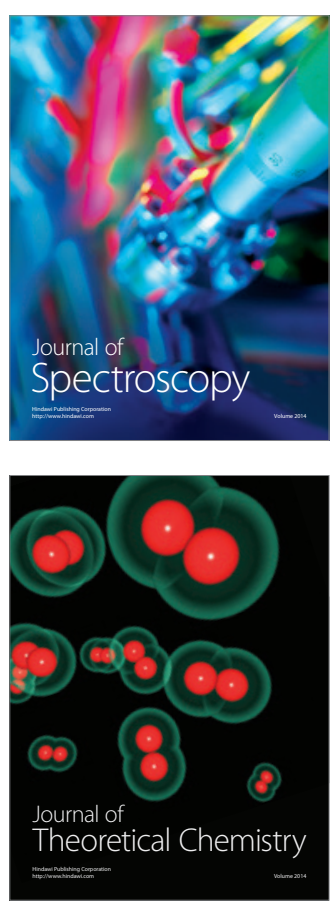
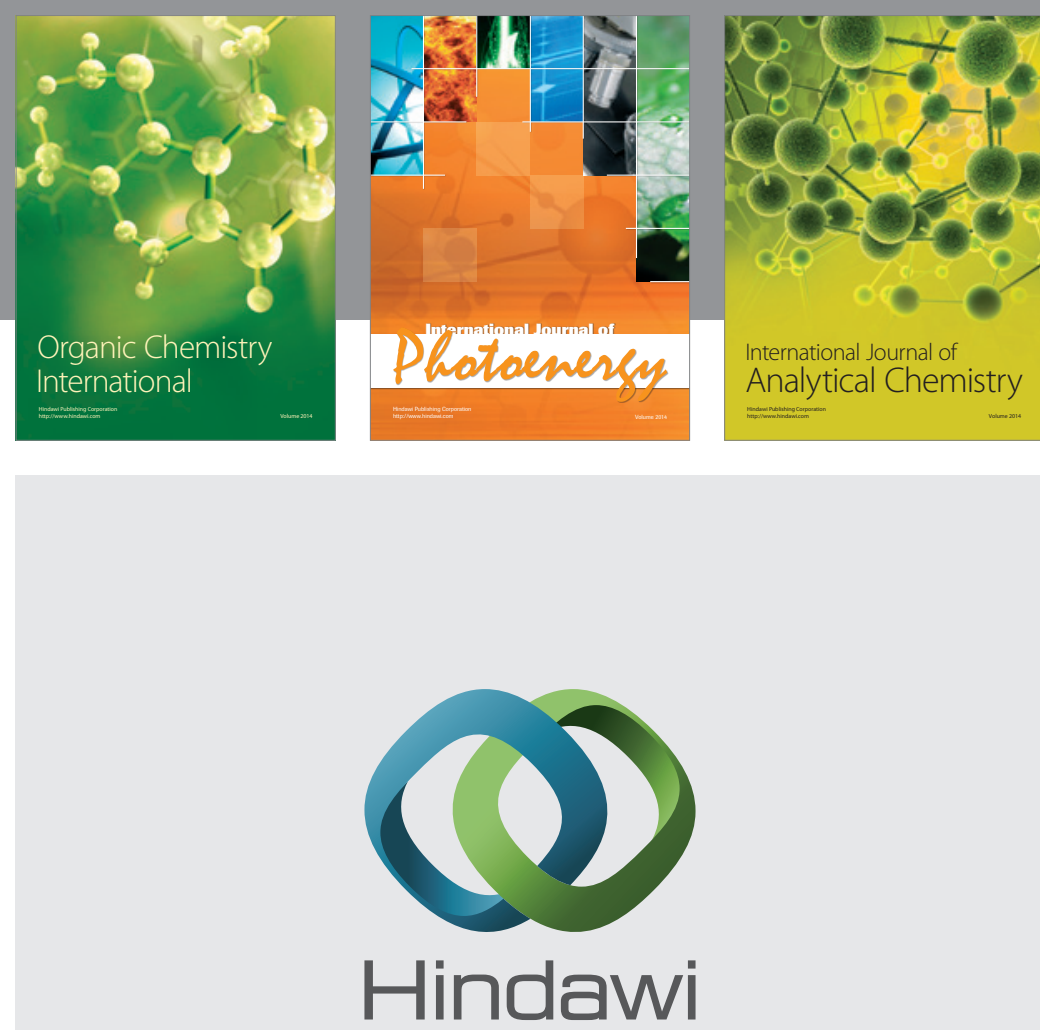

Submit your manuscripts at

http://www.hindawi.com
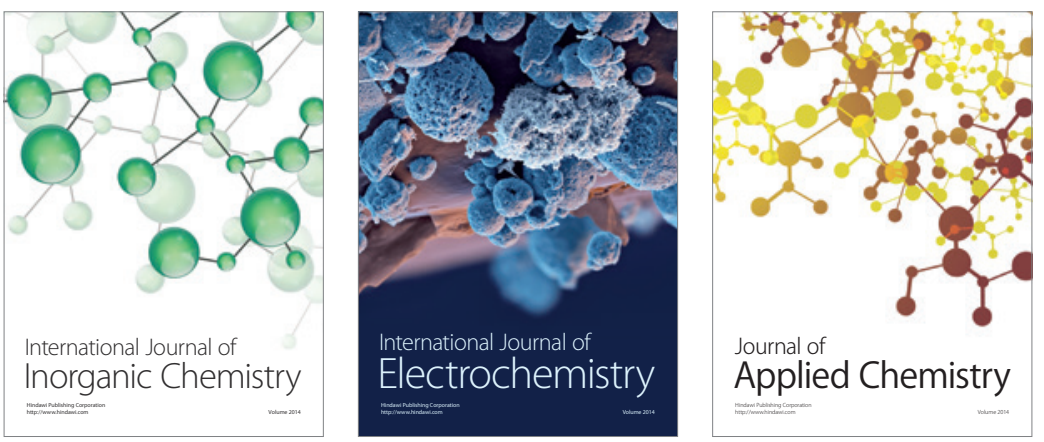

Journal of

Applied Chemistry
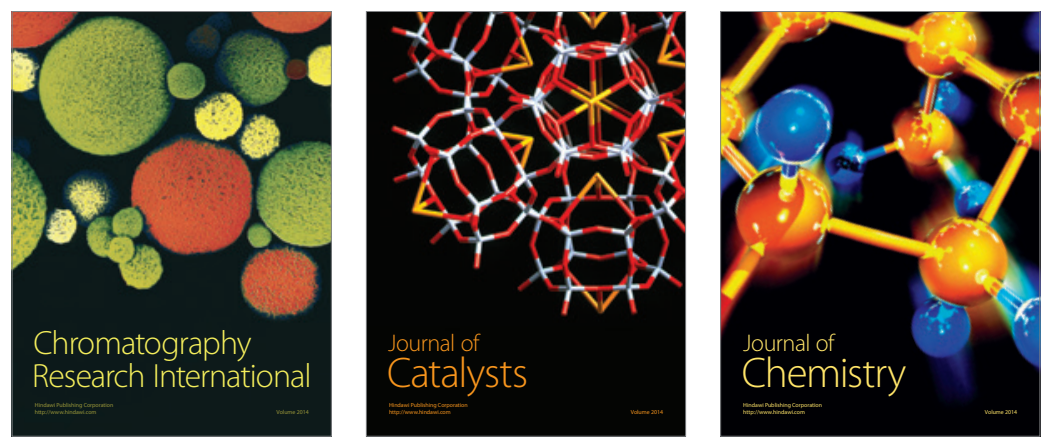
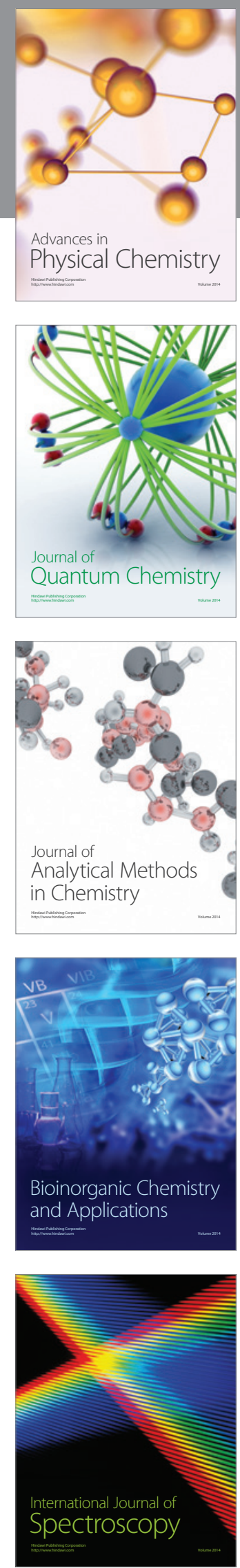